\title{
Novel roles for nasal epithelium in the pathogenesis of chronic rhinosinusitis with nasal polyps*
}

\author{
Marjolein E. Cornet ${ }^{1}$, Katriina Kostamo², Albert B. Rinia ${ }^{1,+}$, Aeilko H. Zwinder- \\ man $^{3}$, Danielle van Egmond ${ }^{1}$, Esther J.J. de Groot ${ }^{1}$, Wytske J. Fokkens', \\ Cornelis M. van Drunen' \\ 'Otorhinolaryngology, Academic Medical Center, Amsterdam, the Netherlands \\ 2 Otorhinolaryngology, Kymenlaakso Central Hospital, Kotka, Finland \\ ${ }^{3}$ Clinical epidemiology, Academic Medical Center, Amsterdam, the Netherlands
}

Rhinology 57: 3, 169 - 179, 2019

https://doi.org/10.4193/Rhin18.128

*Received for publication:

July 5, 2018

Accepted: October 28, 2018

+ Current address: Otorhinolaryngology, ISALA, Zwolle, the Netherlands

Background: Airway epithelial cells have a well-accepted role in the regulation of local inflammatory processes in allergic and innate defence responses. However, their role the pathophysiology of chronic rhinosinusitis with nasal polyps (CRSwNP) is unclear. The objective was to investigate whether potential differences in the mRNA expression profile of nasal epithelia from healthy individuals and from CRSWNP patients would shed new light on disease mechanisms.

Methods: Primary epithelial cells from nasal polyps of 24 affected individuals and from middle turbinates of 9 healthy controls were obtained using magnetic beat assisted isolation and were used for expression profiling using the Human Genome U133 Plus 2.0 Genechip Array.

Results: Multiple gene probes corresponding to 27 genes showed an aberrant expression profile in polyp epithelial cells compared to healthy controls. Most of these genes are linked to pathogenic mechanisms seen in neoplasm formation, including changes in cell-cell adhesion, metabolic processes, cell cycle control, and differentiation. Remarkably, our data additionally suggest a role for maternally expressed genes in the pathogenesis of CRSWNP and reveal two distinct states of polyp epithelium that could not be linked to the presence or absence of atopy in patients or to the level of eosinophilia or neutrophilia of the polyp.

Conclusions: Our data suggest new roles for nasal epithelium in the pathogenesis of CRSwNP.

Key words: epithelium, chronic rhinosinusistis, nasal polyposis, microarray, expression profiling, epigenetics, neoplasm formation, polyp, pathogenesis

\section{Introduction}

Chronic rhinosinusitis with nasal polyps (CRSwNP) is a multifactorial chronic inflammatory disease that is characterized by a mass in the nasal cavity that most often originates from the paranasal sinuses ${ }^{(1)}$. It is a relative common disease with a prevalence of $4-5 \%$ in the general population with typical symptoms comprising nasal congestion, rhinorrhea, hyposmia, and facial pressure. Although the aetiology of CRSwNP is largely unknown, in people with asthma prevalence goes up to $6-15 \%$ and nasal polyps also share typical histological features. Polyps seem to resemble the bronchial mucosa of asthmatic patients with epithelial damage, goblet cell hyperplasia, thickening of the basement membrane, accumulations of extracellular matrix, fibrosis, and in the western population often eosinophil-dominated inflammation ${ }^{(2)}$. Given the active contribution of epithelium to the regulation of local inflammatory responses ${ }^{(3)}$ in this manuscript we have explored the potential contribution of polyp epithelium to the pathogenesis of CRSwNP using micro-array expression profiling.

The potential contribution of nasal epithelium to the pathophysiology of CRSwNP has not been extensively explored, although expression of toll-like receptors and other innate immune response factors is well documented ${ }^{(4)}$. In allergic airway disease there is an established awareness of the role of epithelial cells 
as an active participant in the regulation of local immune responses ${ }^{(5,6)}$. Epithelial cells are able to detect and respond to environmental signals through a wide variety of receptors, while epithelial integrity is still considered an important aspect in maintaining local homeostasis ${ }^{(7)}$. In addition to epithelial involvement in CRSWNP, it has been suggested that the interaction between nasal epithelium and myofibroblasts in CRSwNP could resemble the interaction between bronchial epithelium and smooth muscle cells ${ }^{(8)}$. In asthma the mutual and reciprocal activation within this epithelial mesenchymal trophic unit is thought to contribute to the pathophysiology of the disease. Indeed this link may help to explain the increased prevalence of CRswNP in asthma patients ${ }^{(1)}$. Other processes through which epithelium may directly or indirectly affect CRSwNP would be in the interaction with bacterial biofilms and orchestrations of (innate) immune responses ${ }^{(6)}$.

Previously, we have investigated the role of nasal epithelium in allergic rhinitis to investigate intrinsic differences in expression profile that could contribute to the pathology of disease

(9). Using a similar approach in this study we identified affected genes in CRSwNP related to epithelial integrity, neoplasm formation, and glucose metabolism. Moreover we detected a novel epithelial dichotomy in CRSWNP that is not related to atopic status or to eosinophilic versus neutrophilic inflammation level of the polyp.

\section{Material and Methods}

\section{Study design}

This study was reviewed and approved by the medical ethical committee of the Academic Medical Center (06/062) and all participants signed informed consent. We included 24 CRSwNP patients and 9 controls (Table 1) that were generally healthy and did not have any auto-immune disorders or other relevant comorbidities (e.g. aspirine intolerance) that could affect outcome measures. EP3OS criteria were used for inclusion of CRSwNP patients, while ARIA and GINA guidelines were used to establish allergic and asthma status. Atopy status was determined using the recommended GA2LEN panel of the 20 most common aeroallergens. The CRSwNP patients were operated because of severe symptoms of their disease while controls had non-secreting pituitary adenomas requiring endoscopic surgery and none of the participants had used local and/or systemic steroids four weeks prior to surgery.

\section{Primary epithelial cell culture}

Primary cells were obtained by digesting nasal biopsies or nasal polyps from the participants with $0.5 \mathrm{mg} / \mathrm{mL}$ collagenase 4 (Worthington Biochemical Corp., Lakewood, NJ, USA) for 1 hour in Hanks' balanced salt solution (Sigma-Aldrich, Zwijndrecht, the Netherlands). Epithelial cells were isolated using an anti-EpCAM microbead assisted cell isolation procedure (Miltenyi Biotec,
Table 1. Demographics.

\begin{tabular}{lcccccc} 
& $\begin{array}{c}\text { Total } \\
\text { number }\end{array}$ & Allergy & Asthma & $\begin{array}{c}\text { Aspirin } \\
\text { intole- } \\
\text { rance }\end{array}$ & $\begin{array}{c}\text { Mean } \\
\text { age } \\
\text { (years) }\end{array}$ & $\begin{array}{c}\text { Gender } \\
\text { (M/F) }\end{array}$ \\
\hline Healthy & 9 & 0 & 0 & 0 & 54 & $7 / 2$ \\
CRSwNP & 24 & 10 & 12 & 0 & 45 & $15 / 9$ \\
\hline
\end{tabular}

Bergisch Gladbach, Germany) and grown in T25 cultured with BEGM in fully humidified air containing $5 \% \mathrm{CO}_{2}$ at $37^{\circ} \mathrm{C}$ to $80 \%$ confluence within 2 weeks.

\section{RNA extraction}

Total RNA from each sample was extracted using Trizol (Life Technologies, Inc., Gaitersburg, MD, USA), followed by purification by nucleospin RNA II (Machery-Nagel, Düren, Germany). The RNA concentration was measured on the nanodrop ND-1000 (NanoDrop Technologies inc., Wilmington, DE, USA) and RNA quality was checked on the Agilent 2100 bio-analyzer (Agilent Technologies, Palo Alto, CA, USA).

\section{Microarray data analysis and statistics}

Human Genome U133 Plus 2.0 Genechip Array (Affymetrix inc., Santa Clara, CA, USA) was used in the analysis of the different expression patterns in diseased and healthy nasal epithelium. Technical handling of microarray experiments was performed at the MicroArray Department (MAD) of the University of Amsterdam and array images were acquired using a GeneChip Scanner 3000 (Affymetrix) and analyzed with Affymetrix GeneChip ${ }^{\oplus}$ Operating Software (Affymetrix).

The images and raw data passed manufacturers recommended quality criteria. GeneSpring v13 (Agilent technologies, Santa Clara, CA, USA) expression console was used to extract expression values, perform statistic testing, and analyse data. Expression levels were calculated using robust multi-array average (RMA) algorithm. Differences in expression were determined using unpaired statistical t tests with correction for multiple testing with a false discovery rate of 0.05 using the Westfall-Young procedure.

\section{Immunohistochemistry}

Section of snap frozen biopsies were stained for eosinophils (Clone BMK13 at $0.05 \mu \mathrm{g} / \mathrm{mL}$, Monosan, Uden, the Netherlands) and neutrophils (Elastase at $2.2 \mu \mathrm{g} / \mathrm{mL}$, DACO, Glastrup, Denmark) using Brightvision (Immunologic, Duiven, the Netherlands) as per manufacturer's instructions. All sections were examined by two independent observers blinded to the experimental conditions. The numbers of positively stained cells were counted in the lamina propria (per $\mathrm{mm}^{2}$ ) at a final magnification of 200x. Statistical significance was determined with the Mann-Whitney U-test. 
Table 2. Expression differences between epithelium from CRSwNP patients and healthy controls showing probe identity number (ID), fold change $(\mathrm{FC})$, gene name, and chromosome location. N/A refers to not assigned probes.

\begin{tabular}{|c|c|c|c|c|}
\hline Probe ID & Gene & FC & Gene name & Location \\
\hline 230835_at & KRTDAP & -7.49 & keratinocyte differentiation-associated protein & chr19q13.12 \\
\hline 206642_at & DSG1 & -5.56 & desmoglein 1 & $\operatorname{chr18q12.1}$ \\
\hline 205625_s_at & CALB1 & -4.08 & calbindin $1,28 \mathrm{kDa}$ & chr8q21.3 \\
\hline 206004_at & TGM3 & -4.05 & transglutaminase 3 & chr20q11.2 \\
\hline 220225_at & IRX4 & -3.21 & iroquois homeobox 4 & chr5p15.3 \\
\hline 214536_at & SLURP1 & -2.79 & secreted LY6/PLAUR domain containing 1 & chr8q24.3 \\
\hline 205626_s_at & CALB1 & -2.64 & calbindin $1,28 \mathrm{kDa}$ & chr8q21.3 \\
\hline 212813_at & JAM3 & -2.63 & junctional adhesion molecule 3 & chr11q25 \\
\hline 221328_at & CLDN17 & -2.56 & claudin 17 & chr21q22.11 \\
\hline 231733_at & CARD18 & -2.43 & caspase recruitment domain family, member 18 & $\operatorname{chr11q22.3}$ \\
\hline 212915_at & PDZRN3 & -1.87 & PDZ domain containing ring finger 3 & chr3p13 \\
\hline 217564_s_at & CPS1 & -1.86 & carbamoyl-phosphate synthase 1 , mitochondrial & chr2q35 \\
\hline 205637_s_at & SH3GL3 & -1.84 & SH3-domain GRB2-like 3 & chr15q24 \\
\hline 212730_at & SYNM & -1.83 & synemin, intermediate filament protein & $\operatorname{chr} 15 q 26.3$ \\
\hline 231148_at & IGFL2 & -1.81 & IGF-like family member 2 & $\operatorname{chr} 19 q 13.32$ \\
\hline 238022_at & CRNDE & -1.79 & colorectal neoplasia differentially expressed & $\operatorname{chr16q12.2}$ \\
\hline 207023_x_at & KRT10 & -1.70 & keratin 10 & chr17q21 \\
\hline 213287_s_at & KRT10 & -1.70 & keratin 10 & $\operatorname{chr17q21}$ \\
\hline 231240_at & $\mathrm{DIO} 2$ & -1.51 & deiodinase, iodothyronine, type II & $\operatorname{chr14q24.2}$ \\
\hline 242157_at & CHD9 & -1.49 & chromodomain helicase DNA binding protein 9 & $\operatorname{chr} 16 q 12.2$ \\
\hline 1555773_at & BPIFC & -1.46 & BPI fold containing family $\mathrm{C}$ & chr22q12.3 \\
\hline 227491_at & ELOVL6 & -1.45 & ELOVL fatty acid elongase 6 & chr4q25 \\
\hline 203700_s_at & $\mathrm{DIO} 2$ & -1.43 & deiodinase, iodothyronine, type II & chr14q24.2-3 \\
\hline 231720_s_at & JAM3 & -1.42 & junctional adhesion molecule 3 & chr11q25 \\
\hline 244722_at & $\mathrm{N} / \mathrm{A}$ & 1.27 & Not Assigned & $\mathrm{N} / \mathrm{A}$ \\
\hline 232417_x_at & ZDHHC11 & 1.28 & zinc finger, DHHC-type containing 11 & chr5p15.33 \\
\hline 200704_at & LITAF & 1.33 & lipopolysaccharide-induced TNF factor & chr16p13.13 \\
\hline 200706_s_at & LITAF & 1.37 & lipopolysaccharide-induced TNF factor & chr16p13.13 \\
\hline 238348_x_at & N/A & 1.42 & Not Assigned & $\mathrm{N} / \mathrm{A}$ \\
\hline 202755_s_at & GPC1 & 1.44 & glypican 1 & chr2q35-37 \\
\hline 209522_s_at & CRAT & 1.56 & carnitine O-acetyltransferase & chr9q34.1 \\
\hline 216894_x_at & CDKN1C & 1.58 & cyclin-dependent kinase inhibitor 1C (p57, Kip2) & chr11p15.5 \\
\hline 213182_x_at & CDKN1C & 1.79 & cyclin-dependent kinase inhibitor 1C (p57, Kip2) & chr11p15.5 \\
\hline 219534_x_at & CDKN1C & 1.83 & cyclin-dependent kinase inhibitor 1C (p57, Kip2) & chr11p15.5 \\
\hline 226403_at & TMC4 & 1.84 & transmembrane channel-like 4 & $\operatorname{chr19q13.42}$ \\
\hline 206088_at & LRRC37A3 & 1.90 & leucine rich repeat containing 37 , member $A 3$ & chr17q24.1 \\
\hline 213348_at & CDKN1C & 1.96 & cyclin-dependent kinase inhibitor $1 C$ (p57, Kip2) & chr11p15.5 \\
\hline 228742_at & $N / A$ & 1.98 & Not Assigned & $\mathrm{N} / \mathrm{A}$ \\
\hline
\end{tabular}

\section{Results}

Deregulated expression of epithelial cancer related genes dominate the intrinsic differences between epithelia of healthy controls and CRSwNP patients

In total we identified 35 probe sets with a statistical significant different expression pattern (Table 2) between the concha epithelium of healthy individuals and the epithelium covering nasal polyps of patient with CRSwNP. These probe sets correspond to 27 different genes as the genes for calbindin 1 (CALB1), cyclindependent kinase inhibitor 1C (CDKN1C), iodothyronine deio- 


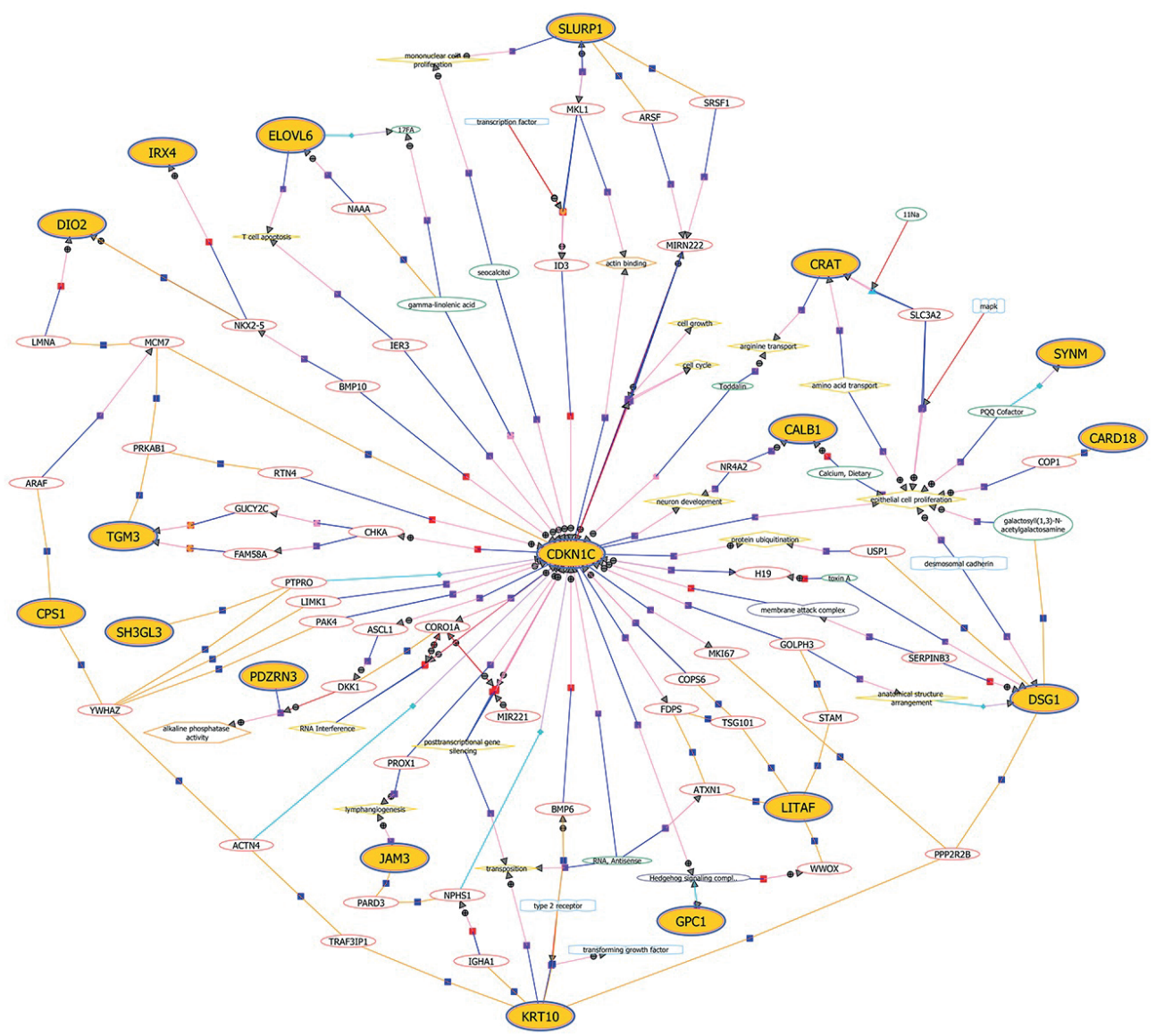

Figure 1. Shortest connect network of genes that are differentially expressed between healthy epithelium and polyp epithelium.

dinase 2 (DIO2), keratin 10 (KRT10), lipopolysaccharide-induced TNF factor (LITAF) and junctional adhesion molecule 3 (JAM3) are represented by multiple probes. The fold change for the probes belonging to each individual gene showed a conserved change of expression. The probes for CALB1 (-4.08 and -2.64 fold), JAM3 (-2.62 and -1.42 fold), KRT10 (-1.70 fold), and DIO2 $(-1.43$ and -1.51 fold) are all down-regulated in polyposis versus healthy controls, whereas in contrast the 4 probes representing CDKN1C $(+1.58,+1.79,+1.83$, and +1.96 fold $)$ and the 2 probes representing LITAF (+1.33 and +1.37 fold) where all up-regulated. A selection of genes was used to validate the microarray expression data by correlating the expression level detected in the microarray with the expression level of an independent real time PCR of random samples. Indeed Table 3 shows a high level of correspondence in both data sets.

Eighteen of 27 deregulated genes form a shortest connection network (Figure 1). The most prominent of these genes is the maternally expressed tumour suppressor gene CDKN1C that previously has been linked to colon polyp formation ${ }^{(10)}$. Indeed, a substantial number of the affected genes have been linked to epithelial neoplasms and related biological processes. The deregulated expression of KRTDAP (keratinocyte differentiation-
Table 3. Correlation coefficients showing high correspondence between microarray and RT-PCR expression levels

\begin{tabular}{|ccc|}
\hline Gene & Correlation & p-value \\
\hline CALB1 & 0.900 & 0.019 \\
\hline TGM3 & 0.913 & 0.015 \\
\hline DSG1 & 0.972 & 0.003 \\
\hline JAM3 & 0.946 & 0.008 \\
\hline SLURP1 & 0.988 & 0.001 \\
\hline KRTDAP & 0.989 & 0.001 \\
\hline
\end{tabular}

associated protein, -7.49 fold), DSG1 (desmoglein 1, -5.56 fold), TGM3 (transglutaminase 3, -4.05 fold), CLDN17 (claudin 17, -2.56 fold), JAM3 (-2.03 fold), SYNM (synemin, -1.83 fold), and KRT10 (keratin 10, -1.70 fold) shows changes in cell adhesion/ ultra-structural complexes ${ }^{(11-17)}$. The deregulation of ELOVL6 (Elongation of Very Long Chain Fatty Acid Elongase 6, -1.45 fold), CRAT (Carnitine acetyltransferase, +1.56 fold), CRNDE (colorectal neoplasia differentially expressed, -1.79 fold), IGFL2 (IGF-like family member $2,-1.81$ fold) point towards changes in insulin, glucose, and lipid metabolism ${ }^{(18-21)}$. Other proteins within our 
Table 4A and B. Expression differences between two types epithelium from nasal polyps showing probe identity number (ID), fold change (FC), gene name, and chromosome location. N/A refers to not assigned probes.

\begin{tabular}{|c|c|c|c|c|}
\hline Probe ID & FC & Gene & Gene name & Location \\
\hline 219975_x_at & -3.28 & OLAH & oleoyl-ACP hydrolase & chr10p13 \\
\hline 233126_s_at & -3.09 & OLAH & oleoyl-ACP hydrolase & chr10p13 \\
\hline 222945_x_at & -2.72 & OLAH & oleoyl-ACP hydrolase & chr10p13 \\
\hline 205597_at & -2.72 & SLC44A4 & solute carrier family 44 , member 4 & chr6p21.3 \\
\hline 225496_s_at & -2.53 & SYTL2 & synaptotagmin-like 2 & chr11q14 \\
\hline 221011_s_at & -2.47 & LBH & limb bud and heart development & chr2p23.1 \\
\hline 1555203_s_at & -2.43 & SLC44A4 & solute carrier family 44, member 4 & chr6p21.3 \\
\hline 221523_s_at & -2.42 & RRAGD & Ras-related GTP binding D & chr6q15-q16 \\
\hline 232914_s_at & -2.32 & SYTL2 & synaptotagmin-like 2 & chr11q14 \\
\hline 203892_at & -2.30 & WFDC2 & WAP four-disulfide core domain 2 & chr20q13.12 \\
\hline 211163_s_at & -2.28 & TNFRSF10C & TNF receptor superfamily, member $10 c$ & chr8p22-p21 \\
\hline 214453_s_at & -2.23 & IFI44 & interferon-induced protein 44 & chr1p31.1 \\
\hline 218885_s_at & -2.19 & GALNT12 & $\mathrm{N}$-acetylgalactosaminyltransferase 12 & chr9q22.33 \\
\hline 206222_at & -2.16 & TNFRSF10C & TNF receptor superfamily, member $10 c$ & chr8p22-p21 \\
\hline 221524_s_at & -2.10 & RRAGD & Ras-related GTP binding D & chr6q15-q16 \\
\hline 223551_at & -2.04 & PKIB & protein kinase inhibitor beta & chr6q22.31 \\
\hline 223423_at & -1.97 & GPR160 & G protein-coupled receptor 160 & chr3q26.2-q27 \\
\hline 235911_at & -1.95 & MFI2 & melanoma associated antigen $\mathrm{p} 97$ & chr3q28-q29 \\
\hline 205259_at & -1.88 & NR3C2 & nuclear receptor subfamily 3 , member $\mathrm{C} 2$ & chr4q31.1 \\
\hline 210538_s_at & -1.74 & BIRC3 & baculoviral IAP repeat containing 3 & chr11q22 \\
\hline 212503_s_at & -1.72 & DIP2C & DIP2 disco-interacting protein 2 homolog $C$ & chr10p15.3 \\
\hline 212686_at & -1.71 & PPM1H & protein phosphatase, $\mathrm{Mg} / \mathrm{Mn}$ dependent $1 \mathrm{H}$ & $\operatorname{chr} 12 q 14.1$ \\
\hline 205278_at & -1.70 & GAD1 & glutamate decarboxylase 1 & chr2q31 \\
\hline 223784_at & -1.70 & TMEM27 & transmembrane protein 27 & chrXp22 \\
\hline 234689_at & -1.69 & PTCHD4 & patched domain containing 4 & chr6p12.3 \\
\hline 227909_at & -1.62 & LINC086-87 & long intergenic non-protein coding RNA 86-87 & chrXq26.3 \\
\hline 204671_s_at & -1.60 & ANKRD6 & ankyrin repeat domain 6 & chr6q14.2-q16.1 \\
\hline 204624_at & -1.59 & ATP7B & ATPase, $\mathrm{Cu}++$ transporting, beta polypeptide & $\operatorname{chr} 13 q 14.3$ \\
\hline 202161_at & -1.56 & PKN1 & protein kinase $\mathrm{N} 1$ & chr19p13.12 \\
\hline 209114_at & -1.56 & TSPAN1 & tetraspanin 1 & chr1p34.1 \\
\hline 209499_x_at & -1.55 & TNFSF12-13 & TNF superfamily, member 12-13 & chr17p13-p13.1 \\
\hline 242931_at & -1.55 & LONRF3 & LON peptidase $\mathrm{N}$-term domain and ring finger 3 & chrXq24 \\
\hline 214667_s_at & -1.54 & TP53І11 & tumor protein p53 inducible protein 11 & chr11p11.2 \\
\hline 202150_s_at & -1.53 & NEDD9 & neural expressed, developmental down-regul. 9 & chr6p25-p24 \\
\hline 207949_s_at & -1.49 & ICA1 & islet cell autoantigen $1,69 \mathrm{kDa}$ & chr7p22 \\
\hline 203332_s_at & -1.49 & INPP5D & inositol polyphosphate-5-phosphatase & chr2q37.1 \\
\hline 212325_at & -1.49 & LIMCH1 & LIM and calponin homology domains 1 & chr4p13 \\
\hline 236656_s_at & -1.47 & $\mathrm{~N} / \mathrm{A}$ & uncharacterized LOC100288911 & chr2p22.3 \\
\hline 244486_at & -1.47 & $\mathrm{~N} / \mathrm{A}$ & Not Assigned & N/A \\
\hline 209500_x_at & -1.42 & TNFSF12-13 & TNF superfamily, member 12-13 & chr17p13-p13.1 \\
\hline 225548_at & -1.38 & SHROOM3 & shroom family member 3 & chr4q21.1 \\
\hline 204276_at & -1.38 & TK2 & thymidine kinase 2 , mitochondrial & chr16q22-23 \\
\hline 205298_s_at & -1.38 & BTN2A2 & butyrophilin, subfamily 2 , member A2 & chr6p22.1 \\
\hline 219952_s_at & -1.37 & MCOLN1 & mucolipin 1 & chr19p13.2 \\
\hline
\end{tabular}




\begin{tabular}{|c|c|c|c|c|}
\hline Probe ID & FC & Gene & Gene name & Location \\
\hline 229253_at & -1.36 & THEM4 & thioesterase superfamily member 4 & chr1q21 \\
\hline 213045_at & -1.34 & MAST3 & microtubule associated ser/thr kinase 3 & chr19p13.11 \\
\hline 212745_s_at & -1.31 & BBS4 & Bardet-Biedl syndrome 4 & chr15q22.3-q23 \\
\hline 241353_s_at & -1.29 & $\mathrm{~N} / \mathrm{A}$ & Not Assigned & $\mathrm{N} / \mathrm{A}$ \\
\hline 224998_at & -1.28 & CMTM4 & CKLF-like MARVEL domain containing 4 & chr16q21-q22.1 \\
\hline 209166_s_at & -1.28 & MAN2B1 & mannosidase, alpha, class 2B, member 1 & chr19cen-q13.1 \\
\hline Probe ID & FC & Gene & Gene name & Location \\
\hline 230835_at & 3.78 & KRTDAP & keratinocyte differentiation-associated protein & chr19q13.12 \\
\hline 1554179_s_at & 3.45 & LYNX1 & Ly6/neurotoxin 1 & chr8q24.3 \\
\hline 203691_at & 2.72 & $\mathrm{PI3}$ & peptidase inhibitor 3, skin-derived & chr20q13.12 \\
\hline 224329_s_at & 2.70 & CNFN & cornifelin & chr19q13.2 \\
\hline 41469_at & 2.57 & $\mathrm{PI3}$ & peptidase inhibitor 3, skin-derived & chr20q13.12 \\
\hline 235272_at & 2.33 & SBSN & suprabasin & chr19q13.13 \\
\hline 1554253_a_at & 2.27 & CERS3 & ceramide synthase 3 & chr15q26.3 \\
\hline 204803_s_at & 2.18 & RRAD & Ras-related associated with diabetes & chr16q22 \\
\hline 206517_at & 2.08 & $\mathrm{CDH} 16$ & cadherin $16, \mathrm{KSP}$-cadherin & chr16q22.1 \\
\hline 204802_at & 2.07 & RRAD & Ras-related associated with diabetes & chr16q22 \\
\hline 1553077_at & 1.94 & SDR9C7 & short chain dehydrogenase/reductase 9 C 7 & chr12q13.3 \\
\hline 213796_at & 1.91 & SPRR1A & small proline-rich protein $1 \mathrm{~A}$ & chr1q21-22 \\
\hline 214536_at & 1.79 & SLURP1 & secreted LY6/PLAUR domain containing 1 & chr8q24.3 \\
\hline 214549_x_at & 1.75 & SPRR1A & small proline-rich protein $1 \mathrm{~A}$ & chr1q21-22 \\
\hline 1570005_at & 1.58 & $\mathrm{~N} / \mathrm{A}$ & Not Assigned & $\mathrm{N} / \mathrm{A}$ \\
\hline 227854_at & 1.50 & N/A & Not Assigned & $\mathrm{N} / \mathrm{A}$ \\
\hline 229215_at & 1.49 & ASCL2 & achaete-scute complex homolog 2 & chr11p15.5 \\
\hline 226177_at & 1.48 & GLTP & glycolipid transfer protein & chr12q24.11 \\
\hline 243388_at & 1.48 & $\mathrm{~N} / \mathrm{A}$ & Not Assigned & $\mathrm{N} / \mathrm{A}$ \\
\hline 202917_s_at & 1.48 & S100A8 & S100 calcium binding protein A8 & chr1q21 \\
\hline 239230_at & 1.48 & HES5 & hairy and enhancer of split 5 (Drosophila) & chr1p36.32 \\
\hline 1555019_at & 1.46 & CDHR1 & cadherin-related family member 1 & chr10q23.1 \\
\hline 211076_x_at & 1.37 & ATN1 & atrophin 1 & chr12p13.31 \\
\hline 1564658_at & 1.33 & NAT16 & N-acetyltransferase 16 (GCN5-related, putative) & chr7q22.1 \\
\hline 206671_at & 1.26 & SAG & S-antigen; retina and pineal gland (arrestin) & $\operatorname{chr} 2 q 37.1$ \\
\hline 234761_at & 1.25 & N/A & Not Assigned & $\mathrm{N} / \mathrm{A}$ \\
\hline 1556753_s_at & 1.23 & N/A & Not Assigned & N/A \\
\hline 1554044_a_at & 1.21 & MRAP & melanocortin 2 receptor accessory protein & chr21q22.1 \\
\hline
\end{tabular}

deregulated gene set that also have been previously reported to be affected in epithelial cancers include CHD9 (chromodomain helicase DNA binding protein 9, -1.49 fold), IRX4 (iroquois homeobox 4, -3.21 fold), SLURP1 (secreted LY6/PLAUR domain containing 1, -2.79 fold), CARD18 (caspase recruitment domain family member 18, -2.43 fold), CPS1 (mitochondrial carbamoylphosphate synthase 1, -1.86), DIO2 (-1.47 fold), and GPC1 (glypican $1,+1.44$ fold) ${ }^{(22-28)}$.

Two distinct epithelial expression profiles in nasal polyps A more detailed representation using hierarchical clustering shows individual expression levels of 35 probes in healthy turbinates and nasal polyps. In addition to the overall differences of up- and down-regulated genes, this analysis suggests that epithelium of nasal polyps can be divided into two clusters as suggested by the tree cluster structure for the different polyps (Figure 2). The differences between the two expression clusters in CRSwNP seem largely dominated, but not uniquely, by expression of KRTDAP that has previously been reported to be involved in squamous cell differentiation and stratification of epithelia (11). 


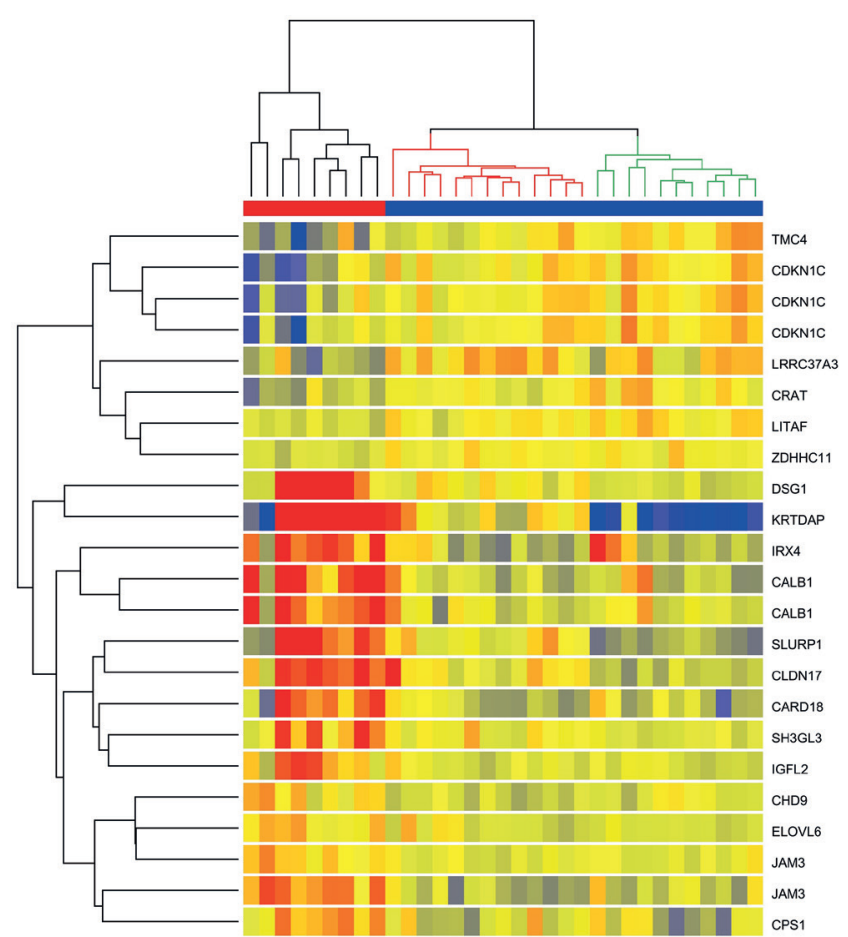

Figure 2. Hierarchical clustering (for probes on the left hand side and for individuals on the top) of the differentially expressed genes between healthy epithelium (black bar) and polyps epithelium (grey bar) showing relative expression (high in red and low in blue). Within the CRSwNP group the two sub-clusters are indicated by the red en green colouring of the dendrogram.

To explore the differences between these potential groups of polyps we compared the expression profiles between these two groups. Indeed, in addition to the differences suggested by expression profiles of KRTDAP, the direct comparison of expression profiles of both groups of polyps reveals 77 probes that correspond to 68 genes that are differentially expressed (Table $4 A / 4 B$ ). The expression profile strengthens the notion of two types of differentiated epithelia, as in addition to KRTDAP we now also detect differential expression of the structural protein CNFN (cornifelin), SPRR1A (small proline-rich protein 1A), and SBSN (suprabasin) that together with HES5 (hairy and enhancer of split 5), RRAD (Ras-related associated with diabetes), SDR9C7 (short chain dehydrogenase/reductase 9C7, ASCL2 (achaetescute complex homolog 2), GLTP (glycolipid transfer protein), S100A8 (S100 calcium binding protein A8), SAG (S-antigen), NR3C2 (nuclear receptor subfamily 3, member C2), BIRC3 (baculoviral IAP repeat containing 3), GAD1 (glutamate decarboxylase 1), ATP7B (ATPase 7B), TSPAN1 (tetraspanin 1), and NEDD9 (neural expressed, developmental down-regulated 9) are typically deregulated in squamous cell epithelial carcinoma's (29-44).

Gene set enrichment analysis furthermore identifies deregulated expression of TNFSF12-13 (TNF superfamily, member 12-13),
TNFRSF10C (TNF receptor superfamily, member 10C), and BIRC3 to TWEAK- (wikipathway 2036, $\mathrm{p}=0.0018$ ) and TRAIL-mediated apoptosis (wikipathway 1772, $\mathrm{p}=0.0065$ ), as important differences between the two types of epithelia. When we further examine the genes that are most affected we note deregulation of LYNX1 (Ly-6/neurotoxin-like protein 1 or SLURP2) and SLC44A4 (solute carrier family 44 , member 4 or CTL4) that, like the previously identified SLURP1, are involved in acetylcholine-mediated neurogenic inflammation ${ }^{(45,46)}$. These two processes (apoptosis and neurogenic inflammation) are indeed often affected in different forms of carcinomas. Their relevance is further supported by representatives of these processes that feature in a shortest connect pathway of all affected genes (Figure 3 ) centred around S100A8 and IFI44 (interferon-induced protein 44). The differences in expression of these genes and processes, however, are not related to differences in level of eosinophils $\left(2.5\right.$ cell $/ \mathrm{mm}^{2}$ in ciliated epithelium, with a range of $0-14.9$ cells $/ \mathrm{mm}^{2}$, versus 6.4 cells $/ \mathrm{mm}^{2}$ in squamous epithelium, with a range of $0-39.2$ cells $/ \mathrm{mm}^{2} ; \mathrm{p}=0.143$ ), neutrophils ( 5.3 cells $/ \mathrm{mm}^{2}$ in ciliated epithelium, with a range of $0-28.7$ cells $/ \mathrm{mm}^{2}$, versus 19.2 cells/ $\mathrm{mm}^{2}$ in squamous epithelium with a range of $0.7-35.1$ cells/ $\left.\mathrm{mm}^{2} ; \mathrm{p}=0.126\right)$, nor in prevalence of atopic comorbidities ( $\mathrm{p}=$ 0.616 ) between the two polyp groups (data not shown).

\section{Discussion}

In this manuscript we provide a detailed overview of intrinsic expression differences between CRSwNP epithelium and healthy control epithelium. The outcome shows that most of these differences are related to changes in ultra-structural organisation, differentiation state, and processes linked to (epithelial) neoplasm formation. In addition to these processes, the data also identified an acetylcholine-centred inflammatory process as potential pathological mechanism in CRSwNP and also suggest a role for epigenetical expression regulation. Moreover, at the epithelial level CRSwNP polyps seem to divide into two groups that are not linked to the presence or absence of allergy or the level of inflammation.

\section{Pathological concepts in CRSwNP}

The deregulated expression of DSG1, JAM3, TGM3, SYNM, and CLDN17 shows that the epithelial integrity defects seen in vivo are cell intrinsic. In allergic disease intrinsic barrier dysfunction is thought to directly contribute to the pathophysiology, as it would facilitate access of allergen. To what extend the changes in adhesion/tight junction proteins play a direct role in the pathology of CRSwNP remains to be explored. On one hand changes in the composition of these adhesion structures could affect their functionality or these changes are part of a compensatory mechanism that tries to counteract the negative effect local inflammatory processes may have on epithelial integrity. On the other hand the loose epithelial structure may in contrast 


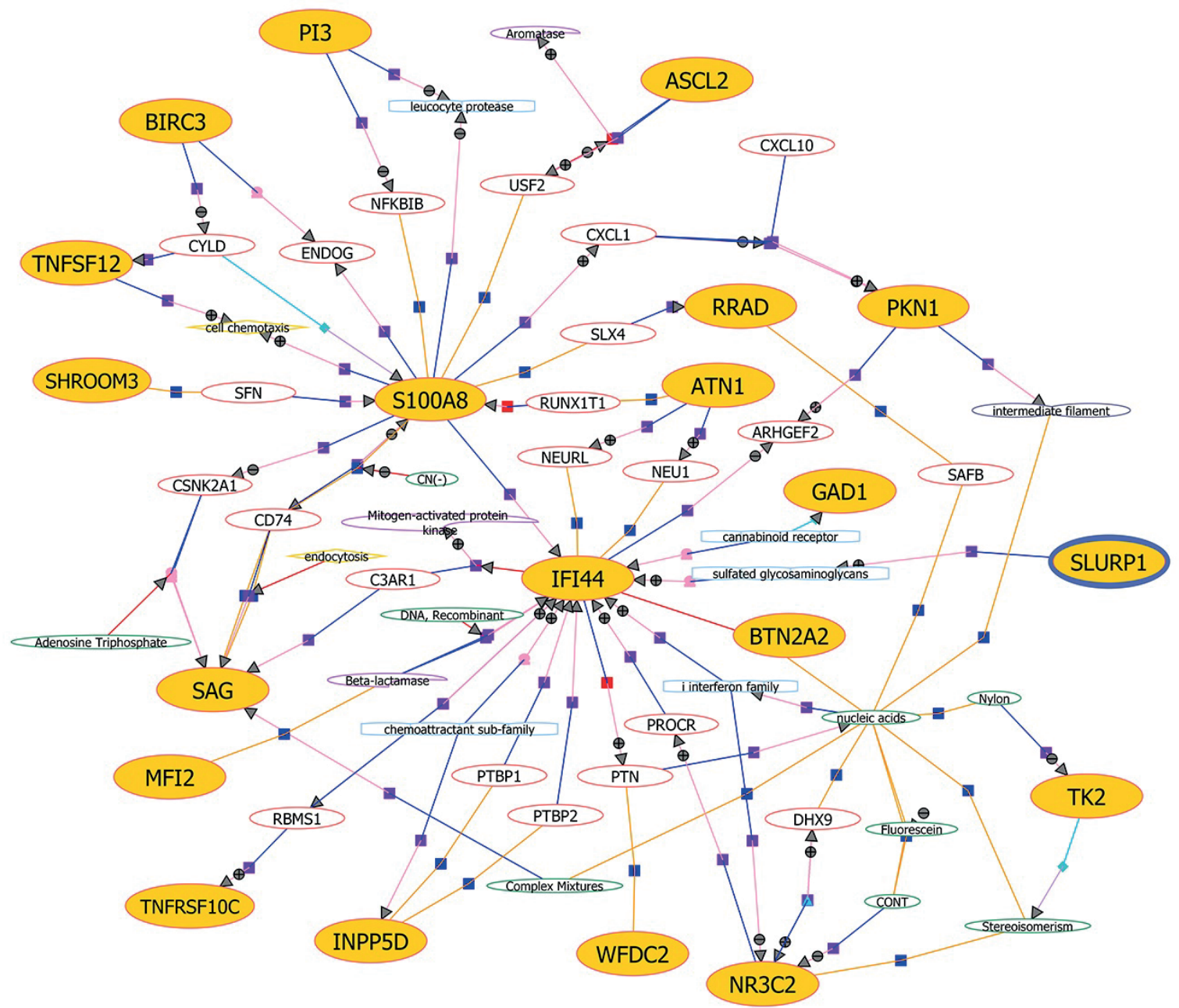

Figure 3. Shortest connect network of genes that are differentially expressed between the two types of polyp epithelium.

even help to drain local inflammation and mitigates its effect. Although the nasal polyps we have studied in this manuscript are not malignant per se, the changes in ELOVL6, CHD9, ASCL2, CRNDE, IGFL2, IRX4, SLURP1, CARD18, CPS1, DIO2, GPC1 and CDKN1C have been linked to cellular transformation ${ }^{(10,18-20,22-28)}$. Interestingly, ELOVL6, DIO2, IGFL2, CALB1, and CRNDE have been linked to metabolic changes seen in a variety of cancers. The most relevant might well be the maternally expressed tumour suppressor gene CDKN1C. Deregulated expression of this gene has been linked to multiple forms of cancer, and mutations in this gene underlie Beckwith-Wiedemann Syndrome ${ }^{(10)}$. A dedicated locus on chromosome 11 (chr11p15.5) is home to the archetypes of epigenetically regulated and growth affecting gene IGF2 (insulin growth factor 2) and the non-coding RNA $\mathrm{H} 19.55$ Indeed in addition to CDKN1C also the deregulated and imprinted gene ASCL2 (achaete-scute complex homolog 2) is located in this region ${ }^{(156)}$.

\section{Neurogenic inflammation}

Although neurogenic inflammation has been studied in relationship to inflammation and neoplasm formation, it has not been extensively considered in CRSwNP. Recently it has become clear that epithelial cells produce and respond to acetylcholine ${ }^{(58)}$. In this light we can see the deregulated expression of SLURP1, Lynx1, and SLC44A4. SLURP1 acts as a potential negative regulator of acetylcholine receptor mediated signalling. In this way it limits epithelial transformation induced by nicotine contained within cigarette smoke, as nicotine is a ligand for the acetylcholine receptor ${ }^{(68)}$ LYNX1 belongs to the same family of proteins and has a similar function as SLURP1. SLC44A4 is a acetylcholine transporter seems specific for acetylcholine secretion ${ }^{(46,59)}$. The precise role of epithelial-centred neurogenic inflammation is not yet fully established. One aspect seems to focus on signalling between adjacent epithelial cells and inflammatory cells in the nasal cavity ${ }^{(58)}$. 


\section{Additional considerations}

Even though the CRSwNP patients included in our study display a mix of varying allergic and/or asthmatic co-morbidities, none of the epithelial deregulated genes show a direct link to allergy. This suggests that at least from an epithelial perspective, allergy is an epiphenomenon and that the epithelial differences we have previously observed in allergic rhinitis do not play a common role in CRSwNP ${ }^{(9)}$.

Cause or effect remains a difficult issue when trying to interpret the differences between the epithelia of CRSwNP patients and health controls. One caviate would be the choice of middle turbinate as control where polyps arise in the ethmoidal region. Unfortunately, obtaining the corresponding region from a healthy control is relatively hard so we opted to use this common control in CRSwNP research. Secondly, in active disease the nasal epithelium will be exposed to many inflammatory triggers that could affect the expression profile. While on one hand these effects could play an important role in the pathological conditions of CRSwNP, on the other hand these differences could just point to innocent bystander effects. We have tried to mitigate some of these aspects by limited culturing of epithelial cells rather than analysing the expression profile in situ or directly after isolation. Although, this approach also allows us to obtain a pure epithelial population, the culture procedure itself may have undocumented effects on the expression profile, and furthermore these effects may differ between diseased and healthy epithelium. For instance, the use of standard submerged culture conditions does not allow the formation of differentiated epithelium which will have consequences for the kind of cell-cell contacts that can be formed. Just like presence of culture media components like corticosteroids will have consequences. Despite these drawbacks, the advantage of this approach of being able to look at stablely transmitted differences induced by CRSwNP in airway epithelial cells and all cells are cultured under identical conditions. We are somewhat reassured that the deregulated genes we have identified can be linked to processes that previously have been hypothesized to have some role in the pathophysiology of the disease ${ }^{(1)}$. The re-affirmation of older hypotheses also gives credence to observations that seem to point to a potential involvement of neurogenic inflammation in the pathophysiology of CRSWNP.

The differences in epithelial expression profile come from our specific patient population. All of our CRSwNP patients have recurrent disease, despite optimal medical treatment, have had multiple previous surgeries, and would as be as far removed from primary polyposis as can be imagined. Although, it is these patients that need our help the most, it may well be that the initial changes that would lead to the formation of nasal polyps could be different from the differences we have discussed here.

\section{Conclusions}

In conclusion, our data identified differences in expression profile between epithelia of CRSwNP patients and that of healthy controls. Although these differences might not necessarily be the cause of the disease, they do point towards new processes that could play a role in the pathophysiology and open new avenues for future research.

\section{Authorship contribution}

MEC, KK, and $A B R$ acquired the data, MEC, $A H Z$, and $C M v D$ analysed the data, $A B R, M E C, D v E$, and EJdeG performed the experiments, KK, ABR, WF, and CMvD conceived the work, MEC, $\mathrm{WF}$, and $\mathrm{CMvD}$ interpreted the results and drafted the manuscript, all authors revised the manuscript and all approved the final version.

\section{Conflict of interest}

None of the authors has anything to disclose related to this manuscript.

\section{References}

1. Fokkens WJ, Lund VJ, Mullol J, Bachert C Alobid I, Baroody F, et al. European Position Paper on Rhinosinusitis and Nasal Polyps 2012. Rhinol Suppl 2012;11:3-298.

2. Dhong HJ, Kim HY, Cho DY. Histopathologic characteristics of chronic sinusitis with bronchial asthma. Acta Otolaryngol 2005;125:169-76.

3. Golebski K, Röschmann Kl, Toppila-Salmi S, Hammad H, Lambrecht BN, Renkonen R, et al. The multi-faceted role of allergen exposure to the local airway mucosa. Allergy 2013:68:152-60

4. van Drunen CM, Mjosberg JM, Segboer $\mathrm{CL}$, Cornet ME, Fokkens WJ Role of innate immunity in the pathogenesis of chronic rhinosinusitis: progress and new avenues. Curr Allergy Asthma Rep 2012;12:120-6.
5. Toppila-Salmi S, van Drunen CM, Fokkens WJ, Golebski K, Mattila P, Joenvaara S, et al. Molecular mechanisms of nasal epithelium in rhinitis and rhinosinusitis. Curr Allergy Asthma Rep 2015;15:495.

6. Vroling $A B$, Fokkens WJ, van Drunen $C M$. How epithelial cells detect danger: aiding the immune response. Allergy 2008;63:1110-23.

7. Zhang N, van Crombruggen K, Gevaert $E$, Bachert C. Barrier function of the nasal mucosa in health and type-2 biased airway diseases. Allergy 2016;71:295-307.

8. Holgate ST, Davies DE, Puddicombe S, Richter A, Lackie P, Lordan J, et al. Mechanisms of airway epithelial damage: epithelial-mesenchymal interactions in the pathogenesis of asthma. Eur Respir J Suppl 2003;44:24s-9s.
9. Vroling $A B$, Jonker MJ, Luiten S, Breit TM, Fokkens WJ, van Drunen CM. Primary nasal epithelium exposed to house dust mite extract shows activated expression in allergic individuals. Am J Respir Cell Mol Biol 2008;38:293-9.

10. Fleisher AS, Meltzer SJ, James SP. Colon polyps in Beckwith-Wiedmann syndrome: role of imprinted genes. Gastroenterology 2000;118: 637

11. Oomizu S, Sahuc F, Asahina K, Inamatsu M, Matsuzaki T, Sasaki M, et al. KDAP, a novel gene associated with the stratification of the epithelium. Gene 2000;256:19-27.

12. Apuhan T, Gepdiremen S, Arslan AO, Aktas G. Evaluation of patients with nasal polyps about the possible association of desmosomal junctions, RORA and PDE4D gene. Eur Rev Med Pharmacol Sci 2013;17:2680-3. 
13. Hitomi K, Presland RB, Nakayama T, Fleckman P, Dale BA, Maki MT. Analysis of epidermal-type transglutaminase (transglutaminase 3) in human stratified epithelia and cultured keratinocytes using monoclonal antibodies. J Dermatol Sci 2003;32:95103.

14. Tőkés AM, Szász AM, Juhász E, Schaff Z, Harsányi L, Molnár IA, et al. Expression of tight junction molecules in breast carcinomas analysed by array PCR and immunohistochemistry. Pathol Oncol Res 2012;18:593606.

15. Yin A, Zhang Q, Kong X, Jia L, Yang Z, Meng $\mathrm{L}$, et al. JAM3 methylation status as a biomarker for diagnosis of preneoplastic and neoplastic lesions of the cervix. Oncotarget 2015;6:44373-87.

16. Noetzel E, Rose M, Sevinc E, Hilgers RD, Hartmann A, Naami A, et al. Intermediate filament dynamics and breast cancer: aberrant promoter methylation of the Synemin gene is associated with early tumor relapse. Oncogene 2010;29:4814-25.

17. Wallace $\mathrm{L}$, Roberts-Thompson L, Reichelt J. Deletion of K1/K10 does not impair epidermal stratification but affects desmosomal structure and nuclear integrity. J Cell Sci 2012:125:1750-8.

18. Matsuzaka T, Shimano H. ELOVL6: a new player in fatty acid metabolism and insulin sensitivity. J Mol Med (Berl) 2009;87:379-84.

19. Muoio DM, Noland RC, Kovalik JP, Seiler SE, Davies MN, DeBalsi KL, et al. Muscle-specific deletion of carnitine acetyltransferase compromises glucose tolerance and metabolic flexibility. Cell Metab 2012;15:764-77.

20. Ellis BC, Graham LD, Molloy PL. CRNDE, a long non-coding RNA responsive to insulin/ IGF signaling, regulates genes involved in central metabolism. Biochim Biophys Acta 2014:1843:372-86.

21. Hartnell A, Heinemann A, Conroy DM, Wait R, Sturm GJ, Caversaccio M, et al. Identification of selective basophil chemoattractants in human nasal polyps as insulin-like growth factor-1 and insulin-like growth factor-2. J Immunol 2004;173:644857.

22. Kim MS, Chung NG, Kang MR, Yoo NJ, Lee $\mathrm{SH}$. Genetic and expressional alterations of CHD genes in gastric and colorectal cancers. Histopathology 2011;58:660-8.

23. Wang W, Lim WK, Leong HS, Chong FT, Lim TK, Tan DS, et al. An eleven gene molecular signature for extra-capsular spread in oral squamous cell carcinoma serves as a prognosticator of outcome in patients without nodal metastases. Oral Oncol 2015;51:35562.

24. Matoso A, Mukkada VA, Lu S, Monahan R, Cleveland K, Noble L, et al. Expression microarray analysis identifies novel epithelial-derived protein markers in eosinophilic esophagitis. Mod Pathol 2013:26:665-76.

25. Tan C, Liu S, Xiang Z. [The expression of CARD18 in apoptin-transfected gastric cancer cells and gastric adenocarcinoma tis- sues]. Xi Bao Yu Fen Zi Mian Yi Xue Za Zhi 2013;29:858-61.

26. Brentnall TA, Pan S, Bronner MP, Crispin DA, Mirzaei H, Cooke K, et al. Proteins that underlie neoplastic progression of ulcerative colitis. Proteomics Clin Appl 2009;3:1326.

27. Arnaldi LA, Borra RC, Maciel RM, Cerutti JM. Gene expression profiles reveal that DCN, DIO1, and DIO2 are underexpressed in benign and malignant thyroid tumors Thyroid 2005; 15:210-21.

28. Melo SA, Luecke LB, Kahlert C, Fernandez AF, Gammon ST, Kaye J, et al. Glypican-1 identifies cancer exosomes and detects early pancreatic cancer. Nature 2015;523:177-82.

29. Heikinheimo K, Kurppa KJ, Laiho A, Peltonen S, Berdal A, Bouattour A, et al. Early dental epithelial transcription factors distinguish ameloblastoma from keratocystic odontogenic tumor. J Dent Res 2015;94:101-11.

30. Michibata H, Chiba H, Wakimoto K, Seishima M, Kawasaki S, Okubo K, et al. Identification and characterization of a novel component of the cornified envelope, cornifelin. Biochem Biophys Res Commun 2004;318:803-13.

31. Shao C, Tan M, Bishop JA, Liu J, Bai W, Gaykalova DA, et al. Suprabasin is hypomethylated and associated with metastasis in salivary adenoid cystic carcinoma. PLoS One 2012;7:e48582

32. Ueo T, Imayoshi I, Kobayashi T, Ohtsuka T, Seno $H$, Nakase $H$, et al. The role of HES genes in intestinal development, homeostasis and tumor formation. Development 2012;139:1071-82.

33. Mo Y, Midorikawa K, Zhang Z, Zhou X, Ma N, Huang G, et al. Promoter hypermethylation of Ras-related GTPase gene RRAD inactivates a tumor suppressor function in nasopharyngeal carcinoma. Cancer Lett 2012;323:147-54

34. Tang S, Gao L, Bi Q, Xu G, Wang S, Zhao G, et al. SDR9C7 promotes lymph node metastases in patients with esophageal squamous cell carcinoma. PLoS One 2013;8:e52184.

35. Hu XG, Chen L, Wang QL, Zhao XL, Tan J, Cui $\mathrm{YH}$, et al. Elevated expression of ASCL2 is an independent prognostic indicator in lung squamous cell carcinoma. J Clin Pathol 2016:69:313-8.

36. Chakraborty S, Nagashri MN, Mohiyuddin SM, Gopinath KS, Kumar A. Gene expression profiling of oral squamous cell carcinoma by differential display rt-PCR and identification of tumor biomarkers. Indian J Surg Oncol 2010;1:284-93.

37. Khammanivong A, Wang C, Sorenson BS Ross KF, Herzberg MC. S100A8/A9 (calprotectin) negatively regulates $\mathrm{G} 2 / \mathrm{M}$ cell cycle progression and growth of squamouscell carcinoma. PLoS One 2013;8:e69395.

38. Yu J, Wang $L$, Zhang $T$, Shen $H$, Dong W, N $Y$, et al. Co-expression of $\beta$-arrestin 1 and NF-kB is associated with cancer progression and poor prognosis in lung adenocarcinoma. Tumour Biol 2015;36:6551-8.

39. Choi YW, Bae SM, Kim YW, Lee HN, Kim YW, Park TC, et al. Gene expression profiles in squamous cell cervical carcinoma using array-based comparative genomic hybridization analysis. Int J Gynecol Cancer 2007;17:687-96

40. Chen YK, Huse SS, Lin LM. Expression of inhibitor of apoptosis family proteins in human oral squamous cell carcinogenesis. Head Neck 2011;33:985-98.

41. Kimura R, Kasamatsu A, Koyama T, Fukumoto C, Kouzu Y, Higo M, et al. Glutamate acid decarboxylase 1 promotes metastasis of human oral cancer by $\beta$-catenin translocation and MMP7 activation. BMC Cancer 2013;13:555

42. Kanzaki A, Nakayama K, Miyashita H, Shirata S, Nitta Y, Oubu M, et al. Mutation analysis of copper-transporting P-type adenosine triphosphatase (ATP7B) in human solid carcinomas. Anticancer Res 2013;23:1913-5.

43. Brabender J, Marjoram P, Lord RV, Metzger $R$, Salonga $D$, Vallböhmer $D$, et al. The molecular signature of normal squamous esophageal epithelium identifies the presence of a field effect and can discriminate between patients with Barrett's esophagus and patients with Barrett's-associated adenocarcinoma. Cancer Epidemiol Biomarkers Prev 2005;14:2113-7

44. Miao Y, Li AL, Wang L, Fan CF, Zhang XP, XU $H T$, et al. Overexpression of NEDD9 is associated with altered expression of E-Cadherin, $\beta$-Catenin and $\mathrm{N}$-Cadherin and predictive of poor prognosis in non-small cell lung cancer. Pathol Oncol Res 2013;19:281-6.

45. Fu XW, Song PF, Spindel ER. Role of Lynx 1 and related Ly6 proteins as modulators of cholinergic signaling in normal and neoplastic bronchial epithelium. Int Immunopharmacol 2015;29:93-8.

46. Song P, Rekow SS, Singleton CA, Sekhon HS, Dissen GA, Zhou M, et al. Choline transporter-like protein 4 (CTL4) links to non-neuronal acetylcholine synthesis. J Neurochem 2013;126:451-61.

47. Li Z, Zhang H. Reprogramming of glucose, fatty acid and amino acid metabolism for cancer progression. Cell Mol Life Sci 2016;73:377-92

48. Matsuzaka T, Shimano HJ. ELOVL6: a new player in fatty acid metabolism and insulin sensitivity. Mol Med (Berl) 2009;87:379-84.

49. Reddy D, Pollock AS, Clark SA, Sooy K, Vasavada RC, Stewart AF, et al. Transfection and overexpression of the calcium binding protein calbindin-D28k results in a stimulatory effect on insulin synthesis in a rat beta cell line (RIN 1046-38). Proc Natl Acad Sci USA 1997;94:1961-6.

50. Emtage $P$, Vatta $P$, Arterburn M, Muller MW, Park E, Boyle B, et al. A secreted family with conserved cysteine residues and similarities to the IGF superfamily. Genomics 2006:88:513-20.

51. Leiria LB, Dora JM, Wajner SM, Estivalet AA, 
Crispim D, Maia AL. The rs225017 polymorphism in the 3'UTR of the human DIO2 gene is associated with increased insulin resistance. PLoS One 2014;9:e103960.

52. Fleisher AS, Meltzer SJ, James SP. Colon polyps in Beckwith-Wiedmann syndrome: role of imprinted genes. Gastroenterology 2000;118:637.

53. Kujan O, Raheel SA, King D, lqbal F. Oral polyp as the presenting feature of Beckwith-Wiedemann syndrome in a child. BMJ Case Rep 2015; bcr2015210758.

54. Anzai $Y$, Koshida $S$, Yanagi $T$, Johnin $\mathrm{K}_{i}$ Takeuchi Y. Neonatal urethral polyps associated with Beckwith-Wiedemann syndrome. Pediatr Int 2013;55:658-61.

55. Smith AC, Choufani S, Ferreira JC, Weksberg R. Growth regulation, imprinted genes, and chromosome 11p15.5. Pediatr Res 2007;61:43R-47R

56. Tian Y, Pan Q, Shang Y, Zhu R, Ye J, Liu Y, et al. MicroRNA-200 (miR-200) cluster regulation by achaete scute-like 2 (ASCL2): impact on the epithelial-mesenchymal transition in colon cancer cells. J Biol Chem 2014;289:36101-15.

57. Tournier JM, Birembaut P. Nicotinic acetylcholine receptors and predisposition to lung cancer. Curr Opin Oncol 2011;23:83-7.

58. Kummer W, Lips KS, Pfeil U. The epithelial cholinergic system of the airways. Histochem Cell Biol 2008;130:219-34.

59. Grando SA. Basic and clinical aspects of non-neuronal acetylcholine: biological and clinical significance of non-canonical ligands of epithelial nicotinic acetylcholine receptors. J Pharmacol Sci 2008;106:174-9.

60. Kostuch M, Klatka J, Semczuk A, Wojcierowski J, Kulczycki L, Oleszczuk J. Analysis of most common CFTR mutations in patients affected by nasal polyps. Eur Arch Otorhinolaryngo 2005;262:982-6.

61. McGarvey LP, Butler CA, Stokesberry S, Polley L, McQuaid S, Abdullah H, et al. Increased expression of bronchial epithelial transient receptor potential vanilloid 1 channels in patients with severe asthma. J Allergy Clin Immunol 2014;133:704-12.
62. Baudoin T, Kalogjera L, Hat J. Capsaicin significantly reduces sinonasal polyps. Acta Otolaryngol 2000;120:307-11.

63. Gevorgyan A, Segboer C, Gorissen R, van Drunen CM, Fokkens WJ. Capsaicin for nonallergic rhinitis. Cochrane Database Syst Rev 2015;7:CD010591.

Marjolein E. Cornet

Department of Otorhinolaryngology

Amsterdam UMC

1100 DD Amsterdam

The Netherlands

Tel: +31-20-566 4721

E-mail:m.e.cornet@amc.nl 